\title{
The efficacy of live infectious bursal disease vaccines in commercial 10 days old chicks.
}

\author{
M. M. Amer ${ }^{1}$, K. M. El-Bayomi ${ }^{2}$, Wafaa A. Abdel-Ghany ${ }^{1}$, M. A. Kotkat $^{2}$ \\ , Sherein S. Abdel-Gaied ${ }^{3}$, M. A. Shakal ${ }^{1}$ \\ ${ }^{1}$ Poultry diseases department, Faculty Veterinary Medicine, Cairo University, Egypt. \\ 2 Poultry diseases department, National Research Center, Dokki and ${ }^{3}$ Pathology department, \\ Faculty Veterinary Medicine, Cairo University, Egypt.
}

\begin{abstract}
The efficacy of four infectious bursal disease virus (IBDV) vaccines including intermediate (D78) and intermediate plus (228E, IBD-Blen and Bursa-Vac+) were compared in priming vaccination of 10 days commercial old male layer chicks. There were different parameters were measured for testing these vaccines including; the immunogenic efficacy, the effect on performance, organ (bursa, spleen, and proventriculus) body weight index as well as histopathological examination of bursa, spleen, proventriculus and thymus. Chick was received a dose of $10^{2}$ EID $_{50}$ from one IBDV vaccine out of $228 \mathrm{E}$, IBD-Blen or Bursa-Vact, while D78 dose was $10^{4}$ EID $_{50}$. The results cleared out that all the tested vaccines passed through the maternal derived antibodies $2480.133+156.3$. All vaccines stimulate antibody formation as measured by ELISA test. The used vaccines not affect markedly body weight and feed intake, as there were no significant differences between the control group and the vaccinated ones in the mean body weight and the feed conversion rate. Furthermore, the bursa: body weight index of vaccinated groups were generally less than those of control one at all intervals, while the spleen and proventriculus: spleen: body weight index of vaccinated groups was higher than control on at the end of the observation period. The used vaccines induced histopathological changes in bursa, spleen, proventriculus and thymus glands. These results indicated that all tested vaccine are of value in vaccination of commercial chicks from vaccinated breeders.
\end{abstract}

Infectious bursal disease (IBD) was firstly reported in Gumboro area, Delaware, USA (Cosegrove, 1962) since the mid 1950s, then it rapidly spread allover the world (Faragher, 1972; Okoye, 1984; Saif et al., 2003). IBD becomes a disease of a great concern as it induces severe economic losses for poultry industry due to immunosuppression (Allan et al., 1972 ; Faragher et al., 1974), deaths ranged 3-3\% (Bygrave and Fraghar, 1970) or even 100\% (Chettle et al., 1989; El-Batrawi, 1990; Van den Berg et al., 1991 ; Eterradossi et al., 1992), growth retardation (Mcilroy et al., 1989) and increased condemnation rate at processing as a result of muscular haemorrhages (Saif et al., 2003). The most susceptible age for IBD virus (IBDV) infection in chickens is 3-6 weeks old and the virus causes severe immunosuppresssion due to destruction of lymphoid organs (mainly the bursa of fabricious) and some other lymphoid organs (Mazzariegos et al., 1990). The first appearance of variant IBDV strains was in 1984 and the very virulent (vv) IBDV strains was in
1989 (Rosenberger and Cloud, 1986; Rosenberger et al., 1987; Saif et al., 2003), as these strains can infect the birds less than 3 weeks of age inducing subclinical infection without signs or macroscopic bursal lesions, however, the infection at this time causes severe immunosuppresssion (Winterfield et al., 1983). The IBDV is very stable in the environment and difficult to be destroyed by the standard methods of sanitation and disinfection (Winterfield et al., 1983). So prevention of infection in chicken based mainly on vaccination as established by Saif et al. (2003). There are two types of IBD vaccines; inactivated and living ones. Inactivated vaccine is used for vaccination of adult hens to protect the progeny at the fist three weeks of age (O'Brien, 1976; Wyeth and Cullen, 1978; Eidson, 1980; Naqi et al., 1983; Box, 1988 ; Bruce et al., 1992). Live vaccines are essentially intended for prevention of IBDV infection in young chickens. Living vaccinal strains of IBDV vary in virulence from mild, intermediate, intermediate-plus to hot and its use on the level 
of maternal antibodies (Thronton and Pattison, 1975; Naqi et al., 1980 and 1983; Giambrone and Clay, 1986; Tsukamoto et al., 1995). Both mild and intermediate live vaccinal strains of IBDV are neutralized by maternal antibodies (Rinaldi et al., 1974; Winterfield and Thacker, 1978; Weyth and Chettle, 1990; Tsukamoto et al., 1995), but the intermediate strain vaccines are superior to mild vaccines in induction of immunity in the presence of maternal antibodies (Mazzariegos et al., 1990). Chicks with high maternal immunity may require hot IBDV strain vaccines to induce active immunity (Winterfield et al., 1980); however, this strain can induce immunosuppresssion (Thronton and Pattison, 1975; Muskett et al., 1979; Henry and Williams, 1980; Thangavelu et al., 1998). Chicks with low or no maternal immunity can be protected by using live mild or intermediate IBDV vaccinal strains (Solano et al., 1986).

Although both live and inactivated vaccines have been developed to control IBD in intensively grown poultry production, difficulties may occur in implementing these vaccines in combination with efficient sanitary measures under field conditions. Such difficulties may explain why IBD-induced immunosuppresssion is still frequently encountered and represents a major threat to the control by vaccination of other infectious diseases affecting intensively grown poultry farms (Lasher and Shane, 1994). So, this work was carried out to investigate the effect of live IBDV vaccines intermediate (D78) and intermediate plus (228E, IBD-Blen and Bursa-Vac + ) strains on the immunogenic response, the bird's performance, organ (bursa, spleen, proventriculus): body weight index as well as histopathological changes of 14 days old male layer chicks that have maternal antibodies to IBDV.

\section{Materials and methods}

Experimental chickens. One day old, 185 male layer type (LCL) chicks obtained from El-Wady poultry company, Giza, Egypt were used. The birds were floor reared on separate disinfected rooms and commercial starter balanced ration. Feed and water were given adlibitum.

Infecious bursal disease (IBD) vaccines. The following commercial Freeze dried live intermediate strains of IBDV were used: Nobilis Gumboro strain (D78), batch number, 068081j01. Intervet International, B. V. Boxmeer, Holand. Intermediate plus vaccine, Nobilis Gumboro strain (228E), batch number, 06802Gj01.
Intervet International, B. V. Boxmeer, Holand. Intermediate plus vaccine strain (2512) IBDBlen, batch number, 2707N2DKA, Phylaxia, Sanofi Vet. Biol. Co. Ltd, Hungary under USA Liscense. Intermediate plus vaccine strain (G603) Bursa-Vac+, batch number, 341/06, Shering-Plough Animal Health, Millsboro, Delaware, USA

Titration of the used IBD vaccines. The viral IBD vaccinal strains were propagated on the chorioallantoic membrane of 10-11 days old specific pathogen free embryonated chicken eggs (ECEs) obtained from free farms (Koum Osheim, El-Fayoum, Egypt). The inoculation was done according to (Villegas and Purchase, 1989), the titer was expressed as $50 \%$ embryo infective dose (EID50) per $\mathrm{ml}$ and it was calculated as Reed and Meunch (1938).

Determination of the antibody titers to IBD vaccines. At day old, just before immunization ( 0 hour) at 10 days of age and also at 17, 24, 31, 36 and 41 days old representing 7, 14, 21, 26 and 31 days post vaccination (PV) the antibody titers were assessed using commercially available Enzyme linked immunosorbent assay (ELISA) kits (IDEXX, 1 DEXX Drive, Westbrook, Marine 04092 USA, US Vet. License number 313 , product code 5040. ELISA test was carried out according to the manufacturer instructions as following:

Preparation of samples. Test samples were diluted 5 hundred fold (1:500) with sample diluents prior to being assayed. Tips were changed for each sample and samples thoroughly mixed prior to dispensing into the coated figure.

Test procedure. One hundred $\mu$ l of undiluted positive control were dispensed into appropriate wells of the figure, and then the figure was incubated for 30 minutes at room temperature. Each well was washed with approximately 350 $\mu 1$ of distilled or deionzed water for 3-5 times, $100 \mu \mathrm{l}$ of goat anti-chicken horseradish peroxidase conjugate was dispensed into each well followed by incubation for 30 minutes at room temperature. Each well was washed again with approximately $350 \mu \mathrm{l}$ of distilled or deionized water for 3-5 times. One hundred $\mu \mathrm{l}$ of TMP substrate was added to each well. The figure was incubated for 15 minutes at room temperature and finally $100 \mu \mathrm{l}$ of stopping solution was dispensed into each well to stop the reaction. ELISA reader (Dynatech MR-700) was blank with air and absorbance values were measured and recorded at $650 \mathrm{~nm}$ wavelength. 
ELISA reading. The difference between the positive control mean and negative control mean ( $\mathrm{PCx}-\mathrm{NCx})$ should be greater than 0.075 . The negative control mean absorbance should be less or equal to 0.150 . The relative level of antibodies in serum samples were determined by calculating serum samples to positive $(\mathrm{S} / \mathrm{P})$ ratio.

Interpretation of results. Serum samples with $\mathrm{S} / \mathrm{P}$ ratios of less than or equal to 0.2 was considered negative. S/P ratios greater than 0.2 (titer greater than 396) was considered positive and indicated vaccination or other exposure to IBDV.

Vaccination of chicks. After titration of the used vaccines, each chick/group was received 102 EID50/ $0.1 \mathrm{ml}$ for each 228E, IBD-Blen and Bursa-Vac+ live intermediate plus IBDV vaccines, but a dose of $10^{4} \mathrm{EID}_{50} / 0.1 \mathrm{ml}$ was given for live intermediate D78 IBDV vaccine. The chicks were vaccinated at 10 days of age via eye instillation.

Determination of the organ. body weight index. The bursa index was calculated according to Sharma et al., (1989) Chicks with bursa : body weight index lower than 0.7 was considered suffering from bursal atrophy (Lucio and Hitchner, 1979). Similarly, the spleen and proventriculus: body weight index were measured.

Experimental design. A total of 185 , day old commercial male layer (LCL) chicks that possessed maternal antibodies to IBDV were used. The birds were floor reared and given feed and water adlibitum. At the first day of life, 10 birds were randomly selected then sacrificed and the sera were collected to determine the titer of maternal antibodies. The birds were vaccinated at 5 days of age against Newcastle disease using HB1 via eye drop method. At 10 days of age, 15 blood samples were collected from the wing veins and the sera were separated for determination of the titer of antibodies at the $(0$ hour) just before immunization (pre immunization) then these birds were weight, at the same time the amount of feed intake was calculated. The remaining (175) chicks at 10 days old were randomly divided into 5 equal separate groups in clean and disinfected rooms; each group was consisted of 35 chicks. Chicks of group (1) were kept as non-vaccinated control. While each chick of group 2, 3, 4 and 5 were received IBDV vaccine 228E, D78, IBD-Blen, and Bursa-Vac+, respectively via eye drop instillation. All the groups were observed after vaccination for signs and mortalities.
Furthermore, individual blood sample for serum after recording of body weight were of control and vaccinated group at 17,24, 31, 36 and 41 days old (7, 14, 21, 26 and $31 \mathrm{PV})$. The weekly group feed was determined. Three birds / group at the previous intervals were randomly selected and each bird was weighed, sacrificed and weight of its bursa, spleen and proventriculus was detected to calculate the organ/ body weight index. Moreover, bursa, spleen, proventriculus and the thymus collected for histopathological examination and lesion score.

Histopathological examination. The Collectedd bursae, spleens, Thymus glands and proventriculus were fixed in $10 \%$ formol saline and saubjected to histopathologicak preparation and examination as described by Bancroft and Steven (1996). The severity of lymphoid lesions was scored (0-4) as described by Sharma et al., (1989).

Statistical analysis. The obtained results were statistically compared and evaluated according to Steel and Torrie (1960).

\section{Results and Discussion}

In this study, we directed our work to investigate the immunogenicity of the most popularly used IBDV vaccines (intermediate and intermediate plus strains) in the presence of maternal antibodies. The selected IBDV vaccines were representative for the phylogenitic study for grouping of IBDV vaccines (Dolz et al., 2004). In the other hand Mato et al., (2004) grouped field IBD viruses according to vaccine.

In this study, no clinical signs or mortalities was observed in control non-vaccinated group and the vaccinated ones. Along the whole observation period after vaccination till the end of the experiment and this result may indicating the safety of the used living IBDV vaccines. Similarly Edgar and Cho (1973); Roasales et al., (1989); Thangavelu et al., (1998); Eterradossi et al., (2004) ; Sultan et al., (2006) found that using of live IBDV vaccines could protect the birds from development of clinical signs and mortalities.

The result of serological response to IBDV vaccines was illustrated in Table (1). The result showed that the maternal antibody titer to IBDV in used day old chicks was $(4477.4 \pm 462.1)$, this titer waned to reach $(2480.13 \pm 156.3)$ at 10 days of age (pre immunization). At 7, 14, 21, 26 and 31 days PV, there was an elevation in the antibody titers of all vaccinated groups in comparison with the titer just before immunization. However, the antibody titer was 
gradually decline in the control non-vaccinated group till the end of the experiment. ELISA titers resulted from vaccination with IBDV vaccine (D78) were the lowest at all intervals while the titers of IBDV vaccine (228E) were the highest. This result revealed that all the used live IBDV vaccines were non immunosuppressive and were able to induce antibody levels in chickens with maternal IBDV antibodies in the absence of IBDV. Such result confirmed the findings of Marquardt et al., (1980); Briggs et al., (1986); Solano et al., (1986) ; Van den Berg and Meulemans, (1991). Also, this result was in accord with this reported by Abdel-Alim and Kawkab (2006) who found that live intermediate plus IBDV vaccines were immunogenic with better immune response in eye drop vaccinated groups.

Concerning the results of the mean body weight and the feed conversion rate in the control non-vaccinated and vaccinated groups at 7, 14, 21, 24, 26 and 31 days PV (Table 1), there was no significant differences between the control non-vaccinated group and the vaccinated ones. Moreover, there were no differences between the vaccinated groups in the measured parameters (Naqi et al., 1980).

The results of the bursa, spleen and proventriculus: body weight index were showed in Table (2) and Fig. (1, 2 and 3). The bursa: body weight index of vaccinated groups were generally less than those of control one at all intervals (Table 2 and Fig.1) and this indicated that the used vaccines caused atrophy of the bursa (bursa: body weight index less than 0.7). This result confirmed the results of Ide and Stevenson, (1973); Mazzariegos et al., (1990); Van den Berg, (1991 ; Eterradossi et al., (1992) who reported that intermediate strains of IBDV vaccines were sufficient to induce a significant reduction in bursa: body weight ratio until 33 dpv. IBDV vaccine (Bursa-Vac+), followed by (228E) induced the mildest effect on bursa when compared with the other vaccines (D78 and IBDBlen). This revealed that the severity of bursal lesions was more in the intermediate strains of IBDV vaccine than intermediate plus vaccines (Thangavelu et al., 1998).

Table (2) and Fig. (2) showed that the spleen: body weight index of vaccinated groups was higher than control non-vaccinated group till the end of the observation period (31 days PV) except (IBD-Blen) vaccinated group which showed spleen: body weight index lower than the control and vaccinated groups indicating splenic atrophy.

The proventriculus: body weight index of vaccinated groups was higher than control nonvaccinated group at the end of the experiment (31 days PV) (Table 2 and Fig. 4) and that may be due to the inflammatory reaction of the used IBV vaccines in the proventriculus.

Histopathological examination of tissue sections of birds vaccinated with IBDV vaccine (D78) revealed undetectable changes in bursal tissue at all intervals. No lesions were detected in the proventriculus firstly, followed by submucosal leucocytic infiltration along the whole intervals (Fig.4a). Spleen tissue showed congestion (Figure 4b) and mild necrosis in follicles (Fig.4c). Thymus section showed congested medulla (Fig. 4d) then became apparently normal till the end of experiment.

Birds vaccinated with IBDV vaccine (228E) showed histological lesions in spleen in the form of congestion firstly (Fig. 5a) followed by congestion and necrosis along the observation period (Fig.5b). Thymus tissue showed vacculated cortical cells (Fig.5c) and focal haemorrhages in medulla (Fig. 5d). The Proventriculus showed submucosal edema and fibrosis (Fig. 5e) accompanied with edema and congestion (Fig. 5f).

Samples for histopathology from IBDV vaccine (IBD-Blen) vaccinated group showed that bursal lesions were seen as interfollicular congestion with slight cortical necrosis (Fig.6a). Spleen showed congestion, haemorrhage and necrotic germinal center (Figure $6 \mathrm{~b}$ ) as well as congestion and focal haemorrhagic areas (Fig.6c). Thymus glands revealed only slight medullary necrosis (Fig.6d). The Proventriculus sections showed submucosal haemorrhage and connective tissue proliferation (Fig.6e) moreover, submucosal congestion, edema and fibrosis were also seen (Fig. 6f).

Examined sections of Bursa-Vac+ vaccinated chicks showed only bursal focal interfollicular haemorrhagic areas (Fig.7a). Spleen showed congestion and haemorrhagic areas in between follicles (Fig.7b) also massive necrosis in the white pulbs and germinal centers of most lymphoid follicles were seen along all the intervals PV (Fig.7c). Thymus glands showed slight medullary necrosis and haemorrhages in medulla (Fig.7d). The proventriculus early after vaccination showed submucosal fibrosis with heterophils infiltration 
Table (1): Results of mean body, feed intake and feed conversion rates and ELISA test of birds vaccinated with different IBDV vaccines

\begin{tabular}{|c|c|c|c|c|c|c|c|}
\hline \multirow[b]{2}{*}{$\begin{array}{l}0 \\
7 \\
Z \\
0\end{array}$} & \multirow[b]{2}{*}{ 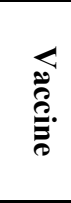 } & \multirow[b]{2}{*}{$\underset{*}{\ominus}$} & \multirow[b]{2}{*}{$\begin{array}{c}\text { Body weight } \\
\text { /gm }\end{array}$} & \multirow[b]{2}{*}{$\begin{array}{l}\text { Feed } \\
\text { intake } \\
\text { /gm }\end{array}$} & \multirow{2}{*}{$\begin{array}{l}* \mathbf{F} . \\
\mathbf{C} . \\
\mathbf{R} .\end{array}$} & \multicolumn{2}{|c|}{ ELISA test } \\
\hline & & & & & & $\begin{array}{c}\text { No of } \\
\text { sampl } \\
\text { es }\end{array}$ & Mean \pm SD \\
\hline \multirow{8}{*}{1} & \multirow{8}{*}{ 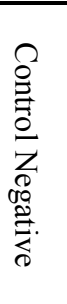 } & 0 & $90.5 \pm 0.66$ & 95 & 1.04 & 15 & $2480.133+156.3$ \\
\hline & & 7 & $167.8 \pm 24.6$ & 243.31 & 1.45 & 15 & $1878.3 \pm 253.1$ \\
\hline & & 14 & $258.1 \pm 33.6$ & 474.92 & 1.84 & 15 & $1231.133 \pm 142.5$ \\
\hline & & 21 & $325.1 \pm 5.03$ & 690 & 2.13 & 15 & $962.26 \pm 127.0$ \\
\hline & & 24 & $372.5 \pm 10.6$ & 815 & 2.18 & & \\
\hline & & 26 & $420.0+14.1$ & 924 & 2.20 & 15 & $312 \pm 70.5$ \\
\hline & & 29 & $455.0+21.2$ & 1114.75 & 2.45 & & \\
\hline & & 31 & $497.5 \pm 17.7$ & 1283.07 & 2.57 & 6 & $205.8 \pm 19.44$ \\
\hline & \multirow{8}{*}{$\begin{array}{l}N \\
N \\
\infty \\
T\end{array}$} & 0 & $90.5 \pm 0.66$ & 95 & 1.04 & & \\
\hline \multirow{7}{*}{2} & & 7 & $168.3 \pm 24.6$ & 274.32 & 1.63 & 15 & $2594.2 \pm 148.9$ \\
\hline & & 14 & $250.0 \pm 33.6$ & 495 & 1.98 & 15 & $3294.2 \pm 215.7$ \\
\hline & & 21 & $324.5 \pm 5.03$ & 707.41 & 2.18 & 15 & $3547.4 \pm 137.4$ \\
\hline & & 24 & $347.5 \pm 10.6$ & 778.4 & 2.24 & & \\
\hline & & 26 & $390.5 \pm 14.1$ & 885.30 & 2.27 & 8 & $3969.3 \pm 165.2$ \\
\hline & & 29 & $442 . \overline{5} \pm 21.2$ & 1101.82 & 2.49 & & \\
\hline & & 31 & $496.0 \pm 17.7$ & 1280 & 2.58 & 5 & $3790.8 \pm 206.6$ \\
\hline \multirow{9}{*}{3} & \multirow{8}{*}{$\underset{\infty}{\nabla}$} & 0 & $90.0 \pm 0.66$ & 95 & 1.04 & & \\
\hline & & 7 & $160.3 \pm 11.0$ & 262.89 & 1.64 & 15 & $2432 \pm 130.2$ \\
\hline & & 14 & $259.3 \pm 21.5$ & 523.78 & 2.02 & 15 & $2986.3 \pm 167.4$ \\
\hline & & 21 & $320.0 \pm 15.0$ & 710.40 & 2.22 & 15 & $3384.8 \pm 112.9$ \\
\hline & & 24 & $387.5 \pm 24.7$ & 871.87 & 2.25 & & \\
\hline & & 26 & $430.0 \pm 14.1$ & 971.80 & 2.26 & 8 & $3602.5 \pm 163.3$ \\
\hline & & 29 & $470.0 \pm 14.1$ & 1156.20 & 2.46 & & \\
\hline & & 31 & $500.0 \pm 21.2$ & 1275 & 2.55 & 5 & $3572.6 \pm 253$ \\
\hline & \multirow{7}{*}{ 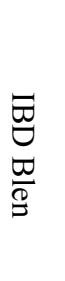 } & 0 & $90.0 \pm 0.66$ & 95 & 1.04 & & \\
\hline \multirow{7}{*}{4} & & 7 & $157 . \overline{6} \pm 9.1$ & 263.19 & 1.67 & 15 & $2536.6 \pm 137.6$ \\
\hline & & 14 & $223.6 \pm 1.5$ & 456.14 & 2.04 & 15 & $3102.5 \pm 167.07$ \\
\hline & & 21 & $289.0 \pm 5.6$ & 635.80 & 2.20 & 15 & $3482.8 \pm 120.9$ \\
\hline & & 24 & $342.5 \pm 11$ & 770.62 & 2.25 & & \\
\hline & & 26 & $382.5 \pm 3.5$ & 868.27 & 2.27 & 8 & $3771.5 \pm 114.05$ \\
\hline & & 29 & $437.5 \pm 3.5$ & 1093.75 & 2.50 & & \\
\hline & \multirow{9}{*}{ 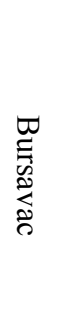 } & 31 & $493 \pm 14.1$ & 1272 & 2.58 & 5 & $3631.4 \pm 180.3$ \\
\hline \multirow{8}{*}{5} & & 0 & $90.0 \pm 0.66$ & 95 & 1.04 & & \\
\hline & & 7 & $166 . \overline{3} \pm 2.5$ & 274.39 & 1.65 & 15 & $2578.2 \pm 136.5$ \\
\hline & & 14 & $237.0 \pm 3.6$ & 464.52 & 1.96 & 15 & $3200 \pm 159.3$ \\
\hline & & 21 & $305.0 \pm 5.0$ & 661.85 & 2.17 & 15 & $3551.1 \pm 117.4$ \\
\hline & & 24 & $347.5 \pm 3.5$ & 778.40 & 2.24 & & \\
\hline & & 26 & $385.0 \pm 7.07$ & 870.10 & 2.26 & 8 & $3922.6 \pm 121.12$ \\
\hline & & 29 & $445.0 \pm 7.1$ & 1103.60 & 2.48 & & \\
\hline & & 31 & $495.0 \pm 7.1$ & 1272 & 2.57 & 5 & $3704.3 \pm 171.9$ \\
\hline
\end{tabular}

*F.C.R: Feed conversion rate.

** DPV= Days Post vaccination. 
Table (2): Results of mean bursa, spleen and proventriculus weights of birds vaccinated with different IBDV vaccines

\begin{tabular}{|c|c|c|c|c|c|c|c|c|}
\hline \multirow{2}{*}{$\begin{array}{l}\text { Gr. } \\
\text { No. }\end{array}$} & \multirow{2}{*}{ 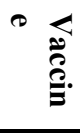 } & \multirow{2}{*}{ *DPV } & \multicolumn{2}{|c|}{ Bursal } & \multicolumn{2}{|c|}{ Spleen } & \multicolumn{2}{|c|}{ Proventriculus } \\
\hline & & & $\begin{array}{l}\text { Ratio } \\
\times 10^{-4} \\
\end{array}$ & Index & $\begin{array}{l}\text { Ratio } \\
\times 10^{-4} \\
\end{array}$ & Index & $\begin{array}{l}\text { Ratio } \\
\times 10^{-4} \\
\end{array}$ & Index \\
\hline \multirow{8}{*}{1} & \multirow{8}{*}{ 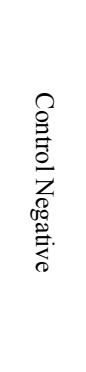 } & 0 & $28.6 \pm 5.50$ & $1.0 \pm 0.0$ & $10.3 \pm 0.57$ & $1.0 \pm 0.0$ & $85.3 \pm 5.85$ & $1.0 \pm 0.0$ \\
\hline & & 7 & $48.6 \pm 6.02$ & $1.0 \pm 0.0$ & $18.0 \pm 5.19$ & $1.0 \pm 0.0$ & $83.6 \pm 3.51$ & $1.0 \pm 0.0$ \\
\hline & & 14 & $55.6 \pm 2.08$ & $1.0 \pm 0.0$ & $17.3 \pm 4.93$ & $1.0 \pm 0.0$ & $67.6 \pm 4.50$ & $1.0 \pm 0.0$ \\
\hline & & 21 & $49.0 \pm 1.0$ & $1.0 \pm 0.0$ & $14.6 \pm 0.57$ & $1.0 \pm 0.0$ & $65.6 \pm 0.57$ & $1.0 \pm 0.0$ \\
\hline & & 24 & $45.0 \pm 2.82$ & $1.0 \pm 0.0$ & $26.5 \pm 2.12$ & $1.0 \pm 0.0$ & $60.0 \pm 9.89$ & $1.0 \pm 0.0$ \\
\hline & & 26 & $48.0 \pm 0.0$ & $1.0 \pm 0.0$ & $29.5 \pm 2.12$ & $1.0 \pm 0.0$ & $65.5 \pm 4.94$ & $1.0 \pm 0.0$ \\
\hline & & 29 & $47.5 \pm 2.12$ & $1.0 \pm 0.0$ & $19.5 \pm 0.70$ & $1.0 \pm 0.0$ & $54.0 \pm 1.41$ & $1.0 \pm 0.0$ \\
\hline & & 31 & $42.0 \pm 1.41$ & $1.0 \pm 0.0$ & $18.5 \pm 0.70$ & $1.0 \pm 0.0$ & $43.0 \pm 2.82$ & $1.0 \pm 0.0$ \\
\hline \multirow{7}{*}{2} & \multirow{7}{*}{$\begin{array}{l}\mathbb{N} \\
\infty \\
\infty \\
T\end{array}$} & 7 & $42.3 \pm 0.57$ & $0.87 \pm 0.01$ & $13.6 \pm 2.08$ & $0.8 \pm 0.12$ & $70.0 \pm 1.0$ & $0.83 \pm 0.01$ \\
\hline & & 14 & $40.40 \pm 1.0$ & $0.71 \pm 0.02$ & $19.3 \pm 1.15$ & $1.13 \pm 0.06$ & $67.6 \pm 0.06$ & $1.01 \pm 0.01$ \\
\hline & & 21 & $37.6 \pm 0.57$ & $0.76 \pm 0.01$ & $16.6 \pm 0.57$ & $1.10 \pm 0.04$ & $59.6 \pm 0.57$ & $0.89 \pm 0.01$ \\
\hline & & 24 & $36.0 \pm 1.41$ & $0.79 \pm 0.03$ & $20.5 \pm 0.70$ & $0.78 \pm 0.02$ & $64.0 \pm 0.0$ & $1.06 \pm 0.0$ \\
\hline & & 26 & $35.0 \pm 1.41$ & $0.74 \pm 0.02$ & $21.0 \pm 0.0$ & $0.75 \pm 0.0$ & $66.0 \pm 2.82$ & $1.04 \pm 0.04$ \\
\hline & & 29 & $30.0 \pm 0.0$ & $0.63 \pm 0.0$ & $25.5 \pm 0.7$ & $1.27 \pm 0.03$ & $60.5 \pm 0.70$ & $1.14 \pm 0.01$ \\
\hline & & 31 & $24.5 \pm 0.70$ & $0.62 \pm 0.02$ & $29.5 \pm 0.70$ & $1.73 \pm 0.04$ & $56.5 \pm 0.70$ & $1.31 \pm 0.01$ \\
\hline \multirow{7}{*}{3} & \multirow{7}{*}{$\underset{\infty}{\forall}$} & 7 & $45.6 \pm 2.51$ & $0.94 \pm 0.05$ & $12.0 \pm 1.0$ & $0.7 \pm 0.06$ & $76.3 \pm 1.15$ & $0.90 \pm 0.01$ \\
\hline & & 14 & $43.3 \pm 2.08$ & $0.77 \pm 0.03$ & $14.3 \pm 0.57$ & $0.84 \pm 0.03$ & $74.6 \pm 2.08$ & $1.11 \pm 0.03$ \\
\hline & & 21 & $34.7 \pm 0.58$ & $0.70 \pm 0.01$ & $17.6 \pm 1.52$ & $1.17 \pm 0.10$ & $62.3 \pm 0.57$ & $0.93 \pm 0.01$ \\
\hline & & 24 & $31.5 \pm 0.70$ & $0.69 \pm 0.02$ & $27.0 \pm 0.0$ & $1.03 \pm 0.0$ & $58.0 \pm 2.82$ & $0.96 \pm 0.04$ \\
\hline & & 26 & $27.0 \pm 1.41$ & $0.57 \pm 0.02$ & $31.0 \pm 1.41$ & $1.10 \pm 0.05$ & $60.5 \pm 0.70$ & $0.96 \pm 0.01$ \\
\hline & & 29 & $20.5 \pm 0.70$ & $0.43 \pm 0.01$ & $23.5 \pm 0.70$ & $1.18 \pm 0.03$ & $48.5 \pm 0.70$ & $0.91 \pm 0.01$ \\
\hline & & 31 & $21.0 \pm 1.41$ & $0.53 \pm 0.03$ & $21.5 \pm 0.70$ & $1.26 \pm 0.04$ & $44.0 \pm 0.0$ & $1.02 \pm 0.0$ \\
\hline \multirow{7}{*}{4} & \multirow{7}{*}{$\begin{array}{l}\ddot{\sigma} \\
\underset{\sigma}{\sigma} \\
\frac{\sigma}{g}\end{array}$} & 7 & $47.3 \pm 2.52$ & $0.98 \pm 0.06$ & $13.3 \pm 0.58$ & $0.78 \pm 0.03$ & $81.7 \pm 8.02$ & $0.97 \pm 0.09$ \\
\hline & & 14 & $42.0 \pm 3.46$ & $0.74 \pm 0.06$ & $20.6 \pm 1.15$ & $1.21 \pm 0.06$ & $69.3 \pm 2.08$ & $1.03 \pm 0.02$ \\
\hline & & 21 & $37.7 \pm 3.51$ & $0.76 \pm 0.07$ & $22.0 \pm 0.0$ & $1.46 \pm 0.0$ & $64.6 \pm 0.57$ & $1.34 \pm 0.64$ \\
\hline & & 24 & $29.0 \pm 1.41$ & $0.64 \pm 0.02$ & $21.5 \pm 0.70$ & $0.82 \pm 0.02$ & $58.0 \pm 1.41$ & $0.96 \pm 0.02$ \\
\hline & & 26 & $28.0 \pm 0.0$ & $0.59 \pm 0.0$ & $17.5 \pm 0.70$ & $0.62 \pm 0.03$ & $56.0 \pm 1.41$ & $0.8 \pm 0.02$ \\
\hline & & 29 & $26.0 \pm 1.41$ & $0.55 \pm 0.02$ & $13.0 \pm 0.0$ & $0.65 \pm 0.0$ & $45.0 \pm 0.0$ & $0.84 \pm 0.0$ \\
\hline & & 31 & $21.10 \pm 0.70$ & $0.55 \pm 0.02$ & $13.0 \pm 0.0$ & $0.76 \pm 0.0$ & $50.0 \pm 0.0$ & $1.16 \pm 0.0$ \\
\hline \multirow{7}{*}{5} & \multirow{7}{*}{ 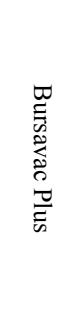 } & 7 & $50.0 \pm 0.0$ & $1.04 \pm 0.0$ & $16.0 \pm 1.0$ & $0.94 \pm 0.06$ & $76.0 \pm 0.0$ & $0.90 \pm 0.0$ \\
\hline & & 14 & $46.7 \pm 1.15$ & $0.83 \pm 0.01$ & $16.7 \pm 0.58$ & $0.98 \pm 0.03$ & $78.0 \pm 0.0$ & $1.16 \pm 0.0$ \\
\hline & & 21 & $36.7 \pm 0.58$ & $0.74 \pm 0.01$ & $17.7 \pm 0.58$ & $1.17 \pm 0.04$ & $58.0 \pm 0.0$ & $0.87 \pm 0.0$ \\
\hline & & 24 & $34.5 \pm 0.71$ & $0.76 \pm 0.01$ & $19.5 \pm 0.71$ & $0.75 \pm 0.02$ & $61.0 \pm 0.0$ & $1.01 \pm 0.0$ \\
\hline & & 26 & $34.0 \pm 0.0$ & $0.72 \pm 0.0$ & $20.0 \pm 0.0$ & $0.71 \pm 0.0$ & $59.0 \pm 0.0$ & $0.93 \pm 0.0$ \\
\hline & & 29 & $31.0 \pm 1.41$ & $0.67 \pm 0.02$ & $20.5 \pm 0.71$ & $1.03 \pm 0.03$ & $51.5 \pm 0.71$ & $0.97 \pm 0.01$ \\
\hline & & 31 & $25.25 \pm 1.41$ & $0.67 \pm 0.04$ & $23.0 \pm 0.0$ & $1.35 \pm 0.0$ & $48.0 \pm 0.0$ & $1.10 \pm 0.01$ \\
\hline
\end{tabular}

* DPV= Days Post vaccination. 
Fig. (1): B ursal ratio of birds vaccinated with diffe re nt IBD vaccines

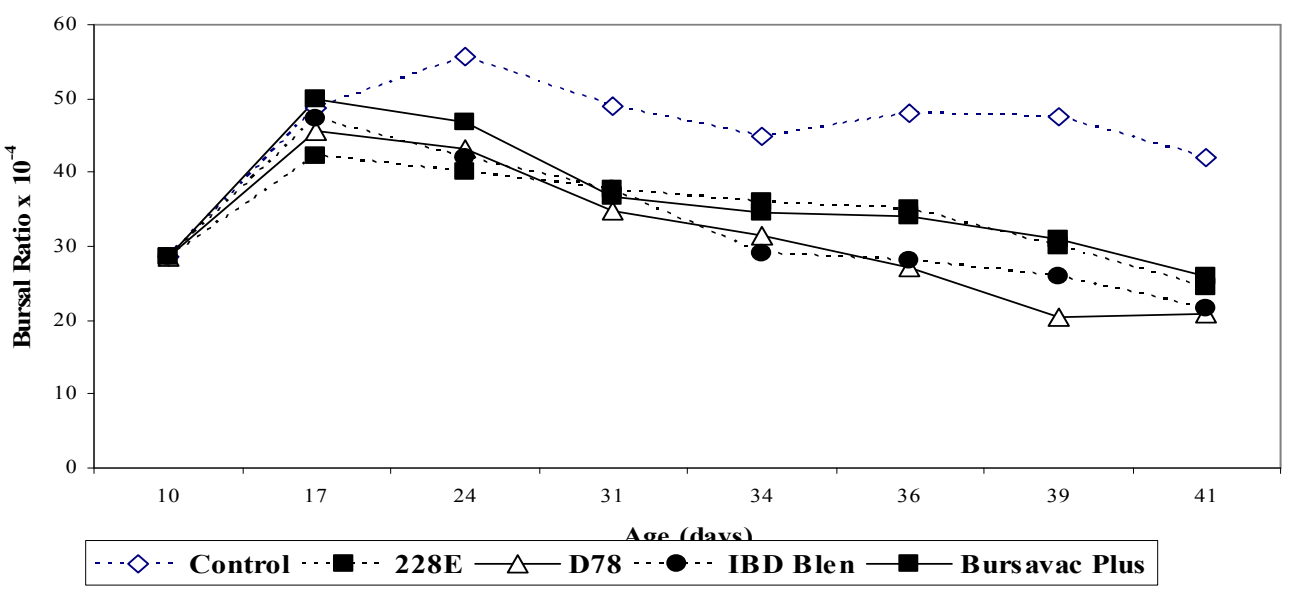

Fig. (2): Spleen ratio of birds vaccinated with different IBD vaccines

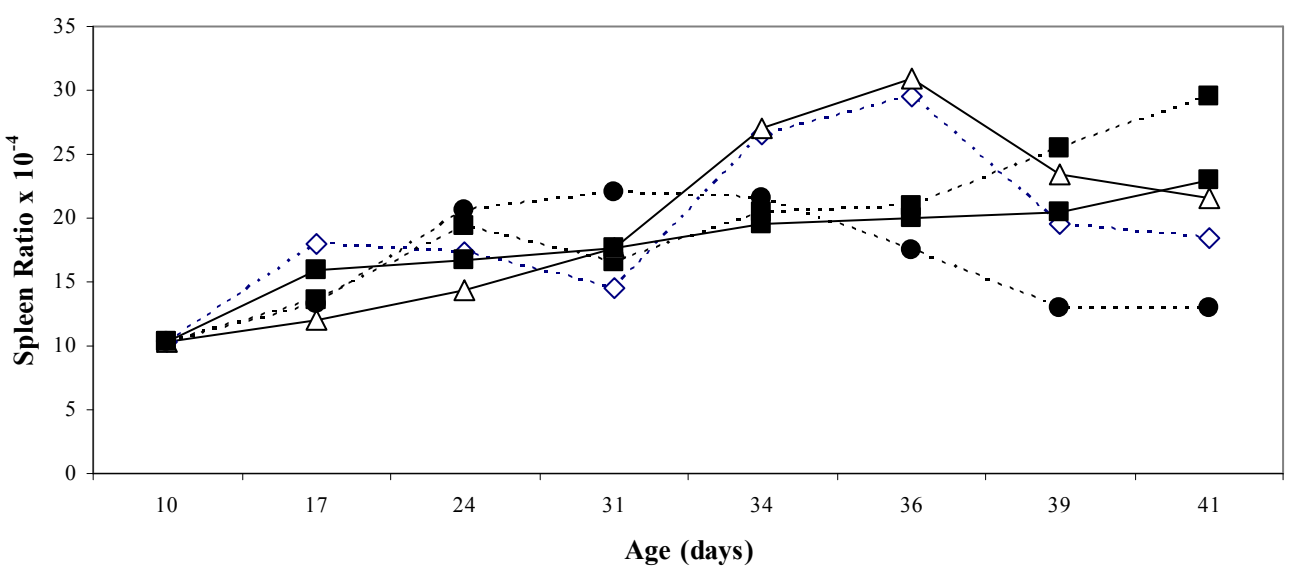

$\cdots \diamond \cdots$ Control $\cdots \bullet \cdots 228 \mathrm{E} \leftrightharpoons-D_{78} \cdots \bullet \cdots$ IBD Blen $\square-$ Bursavac Plus

Fig. (3): Proventriculus ratio of birds vaccinated with different IBD vaccines

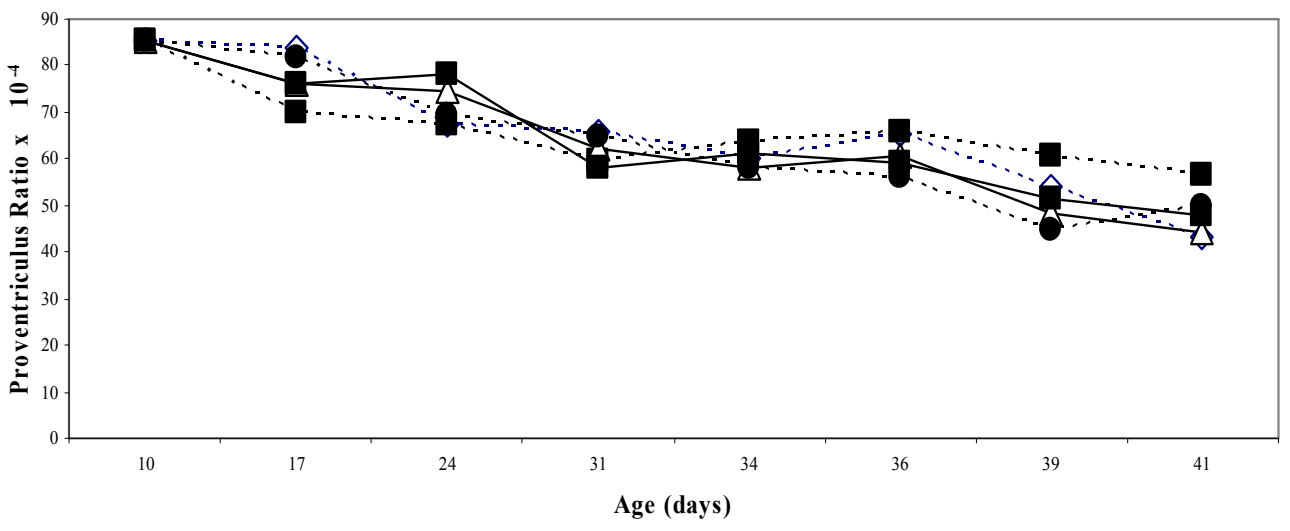

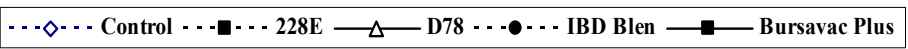



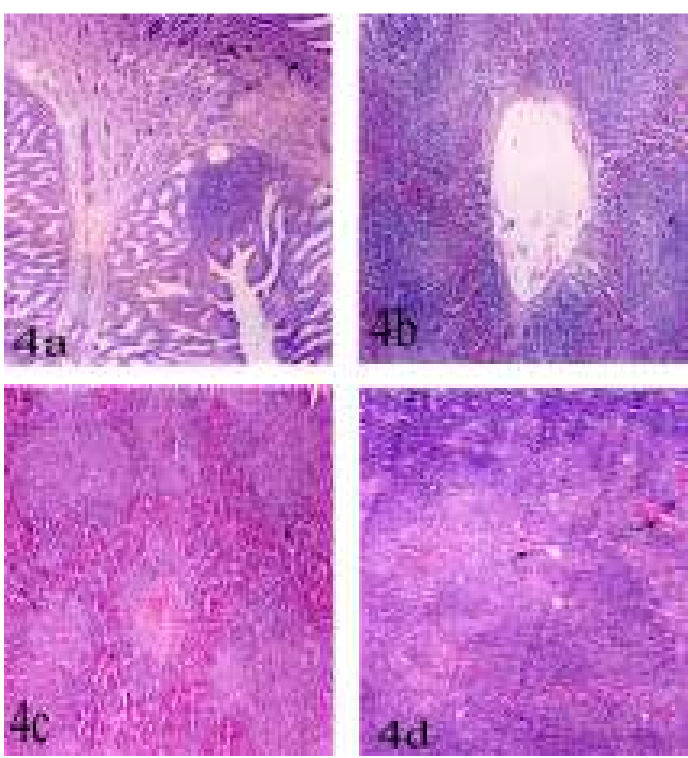

Fig. (4): Sections of chickens vaccinated with D78 (x100) showing:

a) Proventriculus showing leucocytic infiltration (arrow)

(Lesion score: 2 )

b) Spleen showing congestion (Lesion score: 2 )

c) Spleen showing necrosed follicles (Lesion score: 2 )

d) Thymus showing congested medulla (arrow) (Lesion score: 1)
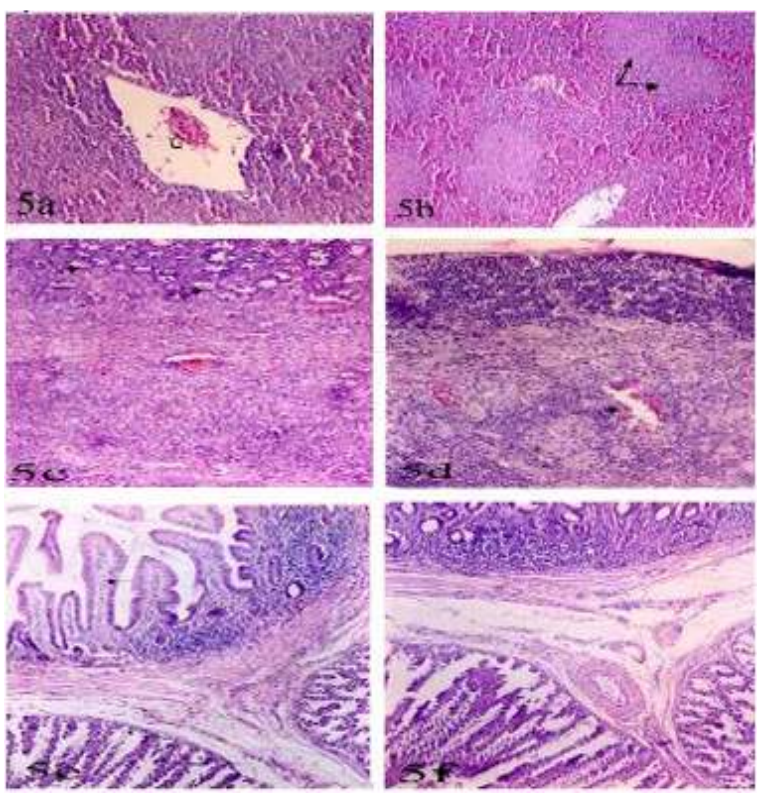

Fig. (5): Sections of chickens vaccinated with $228 \mathrm{E}$ vaccine (H \& E)

a) Spleen showing congestion (c) $\times 200$ (Lesion score: 1 )

b) Spleen showing congestion and necrosis (arrow) (x100) (Lesion score: 2)

c) Thymus showing vacuolated cortical cells (arrow) (x 200) (Lesion score:

d) Thymus showing focal medullary hemorrhage (arrow) (x200) (Lesion score: 2)

e) Proventriculus showing submucosal edema and fibrosis (x100) (Lesion score: 2)

f) Proventriculus showing edema and congestion (x00) (Lesion score: 2 ).
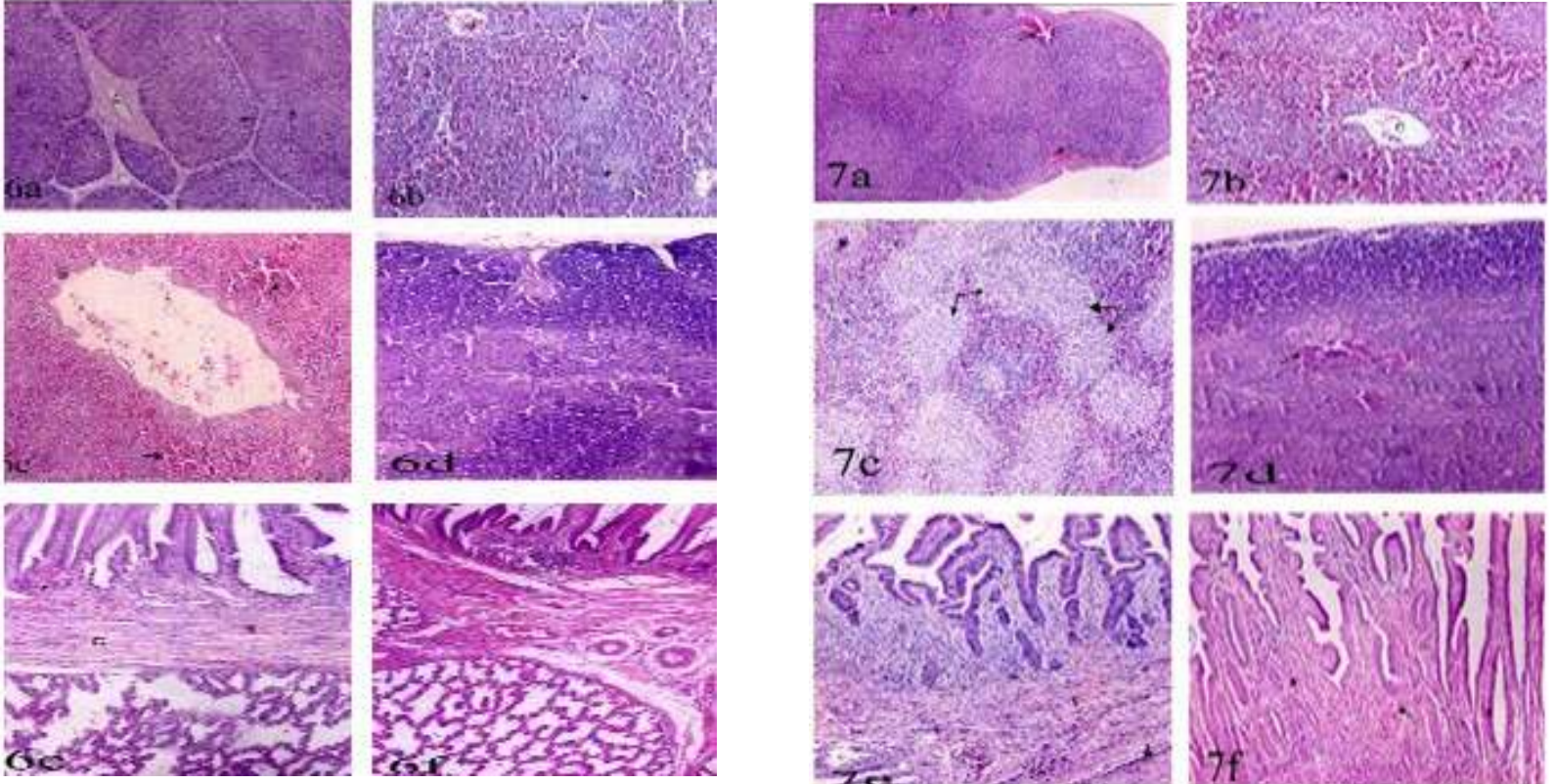

Fig. (6): Sections of chickens vaccinated with IBD-Blen vaccine ( $H$ \& $\mathbf{E})$ :

a) Bursa: congestion (c) and slight necrosed follicular cortex (arrow) (x100) (Lesion score: 1 ).

b) Spleen showing necrosed follicles (arrow) (x100) (Lesion score: 2 ). c) Spleen: hemorrhage (arrow) (x 100) (Lesion score: 1)

d) Thymus showing slight medullary necrosis (x100) (Lesion score: 1 )

e) Proventriculus showing submucosal hemorrhage (arrow) and connective tissue proliferation (c) (x 100) (Lesion score: 2 ).

f) Proventriculus showing congestion and fibrosis $(\mathbf{x 1 0 0})$ (Lesion score: 2 ).

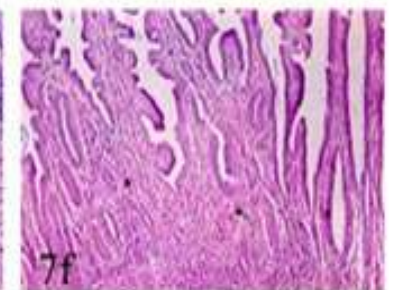
vaccine (H \& E) (x100):

a) Bursa showing focal hemorrhagic areas (arrow) (Lesion score: 1). b) Spleen showing congestion (c) and hemorrhage (arrow) (Lesion score: 1).

c) Spleen showing necrozed follicles (arrow) (Lesion score: 2).

d) Thymus showing hemorrhagic area (arrow) (Lesion score: 1).

e) Proventriculus showing fibrosis (f) and heterophilia (Lesion score: 2).

f) Proventriculus showing heterophilia (arrow) (Lesion score: 2).

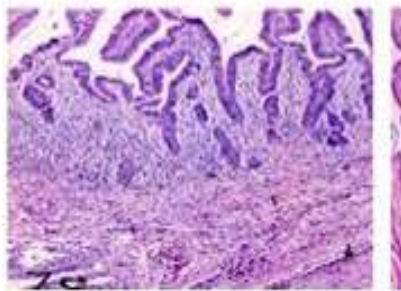

Fig. (7): Sections of chickens vaccinated with bursa-Vac+ 
(Fig.7e) while heterophilic infiltration was seenin the lamina properia later till the end of experiment (Fig. 7e). Histopathological changes in the bursae were recorded previously by ElSergany et al., (1974). Spleenic congested lesions due to these vaccines were observed by Ley et al., (1983); Nunoya et al., (1992) ; Hassan et al., (1996), while necrosis was found by Okoye and Uzoukuw (1981); El-Manakhly and Bekheit (1992). In the other hand, the detected lesions observed in the thymus sections were shown by Sharma et al., (1989) ; Goodwin et al., (1996); Goodwin and Hafner (1997); Shaban (2004) ; Amer et al., (2007). Microscopic lesions observed in the proventriculus were seen by Shaban (2004) and Amer et al, (2007).

The results of the histopathological examination of the bursae, spleens, thymus glands and proventriculus from vaccinated birds indicated that the used living IBDV vaccines were strong enough to cause pathological lesions in the lymphoid organs (Thornton and Pattison, 1975; Ide, 1979; Thangavelu et al., 1998; Mona, 2002).

Comparing results of examined sections clearly pointed out that the IBD blen followed by D78, bursavac plus and 228E affecting tissue of vaccinated chickens.

These finding indicating that the used vaccines have a sever effect on vaccinated 14 days chicks having maternal antibodies as measured by conversion rate, organ; body weight ration and index as well as histopathological findings.

Our results pointed out that the commercially used IBDV vaccines passed through the protective maternal derived antibody titer of vaccinated chicks inducing high antibody titers as measured by ELISA, detectable variation in the measured organ: body weight index as well as lymphoid organ tissue damage when compared with non-vaccinated group. These results may be attributed to the strong vaccinal IBDV strains or unrelatedness between the vaccinal antigen and the maternal derived antibodies.

\section{References}

Abd El-Alim, G. A. and KawKab, A. Ahmed (2006): Efficacy and pathogenicity of three live infectious bursal disease vaccines (intermediate plus strains) in commercial native chickens breed in Egypt. Vet. Med. J., Giza. 54, (3): 649-669.

Allan, W. H.; Faragher, J. J. and Cullen, G. A. (1972): Immunosuppression of the infectious bursal disease agent in chicken immunized against Newcastle disease. Vet. Rec., 90: 511-512.
Amer, M. M. ; El-Bayomi ,K. M.; Kotkat, M. Abd-A ;Wafaa A. Abd El-Ghany; Shakal, M. Abd El-S. and Sherein S. Abd El-Gaied (2007): Isolation, molecular characterization and pathogenicity studies of infectious bursal disease field virus isolates. in press Procc.of the 5th sentific conf. Facult. Vet. Med., BeniSuef Nniveristy 6-9 sept.

Bancroft, J. and Steven, A. (1996): "Theory and Practice of Histopathological technique" $4^{\text {th }}$ Ed., Churchill, Livingstone, NY, London, San Francisco, Tokyo.

Box, P. (1988): Antibody profile of broiler breeder and their progeny immunized with bursal-derived or embryoorigin killed infectious bursal disease vaccine. Proc. Western Poultry Dis. Conf., 37: 21-24.

Briggs, D. J.; Whitfill, C. E.; Skeeles, J. K.; Story, I. and Reed, K. D. (1986):

Application of positive negative ratio method of analysis to quantitative antibody response to infectious bursal disease virus using a commercially available ELISA. Avian Dis., 30 (1): 216-218.

Bruce, I. H.; Butcher, G. D.; Miles, R. D. and Rossi, A. F. (1992): Subclinical

infectious bursal disease in an integrated broiler production operation. J. Vet. Diag. Invest., 4: 406-411.

Baygrave, A. C. and Fragher, J. T. (1970): Mortality associated with Gumboro disease. Vet. Rec., 758-759.

Chettle, N. J.; Smart, J. C. and Wyeth, P. J. (1989): Outbreak of virulent infectious bursal disease in east Anglia. Vet. Rec., 125: 271-272.

Cosegrove, A. S. (1962): An apparently new disease of chickens- avian nephrosis.

Avian Dis., 6: 385-389.

Dolz, R.; Majo, N.; Ordonez, G.; Ponsa, F.; Biarnes, M. and Porta, R. (2004):

Molecular characterization of infectious bursal disease virus isolated in Spain ab. 707., XXII world's Poult. Congress, June 8-13 Istanbul. Turkey.

Edgar, S. A. and Cho, Y. (1973): Immunization of chickens for the control of infectious bursal disease. Poultry Sci., 52: 492-497.

Eidson, C. S. (1980): Vaccination of breeder chickens and their progeny with a live or with an inactivated oil emulsion infectious bursal disease virus vaccine. Develop. Biol. Stand., 51: 251-261.

El-Batrawi, A. M. (1990): Studies on severe out breaks of infectious bursal disease.1-the natural and experimental disease. Proceed. of $2^{\text {nd }}$ Scientific Conf. Egypt. Vet. Poult., 339-252.

El-Manakhly, E. M. and Bekheit, A. B. (1992): The pathology of broilers experimentally infected with infectious bursal disease virus and vaccination against Newcastle disease. Egypt. J. Comp. Pathol. Clin. Pathgol., 5 (1): 55-64.

El-Sergany, H. A.; Ann, Moursi.; Saber, M. S. and Mohammed, M. A. (1974): A preliminary investigation on the occurrence of Gumboro disease in Egypt. Egypt. J. Ve. Sci., 11-17.

Eterradossi, N.; Picault, J. P.; Druin, P.; Michele Guittlet; Rolande

L'hospitalier; and Bennejean; G. (1992): Pathogenicity and preliminary antigenic characterization of 6 infectious bursal disease virus strains isolated in France from acute outbreaks. J. Vet. Med. B., 39: 683-691.

Eterradossi, N.; Gauthier, C.; Reda, I.; Comte, S.; Rivallan, G.; Tonquin, D.;

Biossenson, C.; Lamande, J.; Jestive, V.; Morine, Y.; Cazaban, C. and Borne, B. M. (2004) : Extensive 
antigenic changes in a typical isolate of very virulent infectious bursal disease virus with an antigenically classical live vaccine. Avian Pathol., 33 (4): 423-431.

Faragher. J. T. (1972): Infectious bursal disease of chickens (review). Vet. Bull., 42 (6): 361-369.

Faragher. J. T; Allan, W. H. and Wyeth, P. J. (1974): Immunosuppressive effect of infectious bursal agent on vaccination against Newcastle disease virus. Vet. Rec., 95: 385-388.

Giambrone, J. J. and Clay, R. P. (1986): Evaluation of immunogenicity, stability, pathogenicity and immunodepressive potential of 4 commercial live infectious bursal disease vaccines. Poultry Sci., 65: 1287-1290.

Goodwin, M. A.; Hafner, S.; Bounous, D. I.; Latimer, K. S.; Player, E.C.;

Niagrof, D.; Campagnoli, R. P. and Brown, J. (1996): Viral proventriculitis in chickens. Avian Pathol., 25: 369379.

Goodwin, M. A. and Hafner, S. (1997): Transmissible viral proventriculitis.

In: Diseases of Poultry, $10^{\text {th }}$ Ed. Calnek, B.W.; Barnes, H. J.; Beard, C. W.; Reid, W. M. and Yoder, Jr. H. W. Iowa State University Press, Ames, IA. Pp: 1034-1038.

Hassan, M. K.; Al-Natour, M. Q.; Ward, L. A. and Saif, Y. M. (1996):

Pathogenicity, attenuation and immunogenicity of infectious bursal disease virus. Avian Dis., 40: 567-571.

Henry, C. W. and Williams, W. P. (1980): The detrimental effect of vaccinating parentally immune broilers with a modified live virus vaccine for infectious bursal disease. Avian Dis., 24 (4): 1021-1026.

Ide, P. R. (1979): Infectious bursal agent vaccination of chicks from infectious bursal agent vaccinated dams. Canad. Vet. J., 20 (2): 35-40.

Ide, P. R. and Stevenson, R.G. (1973): Infectious bursal disease in New Brunswick. Cand. J. Comp. Med., 37: 347355.

Keck, L. D.; Skelles, J. K. and McNew, R. W. (1993): Antibody detection in

hatched chicken sera and egg yolk samples by commercial ELISA kits for NDV, IBV, infectious bursal disease and Avian Reo virus. Avian Dis., 37: 825-828.

Lasher, H. N. and Shane, S. M. (1994): Infectious bursal disease. World's Poultry Sci. J., 133-166.

Ley, D.H.; Yamamoto, R. and Bickford, A.A. (1983): The pathogenesis of infectious bursal disease: Serologic, histopathologic and clinical chemical observations. Avian Dis., 27 (4): 1060-1085.

Lucio, B. and Hitchner, S. B. (1979): Infectious bursal disease emulsified vaccine: effect upon neutralizing antibody levels in the dam. Avian Dis., 23: 466-478.

Marquardt, W. W; Johnson, R. B; Odenwald, W. and Schlottober, B. A. (1980):

An indirect enzyme linked immunosorbent assay (ELISA) for measuring antibodies in chickens with infectious bursal disease virus. Avian Dis., 24: 375-385.

Mato, T.; Lomniczi, B. and Palya, V. (2004): Molecular characterization of Hungarian field isolates and vaccinal infectious bursal disease virus strains.

Ab. 725, XXII WPC (2004) 8-13 June Istanbul, Turkey.

Mazzariegos, L. A.; Lukert, P. D. and Brown, J. (1990): Pathogenicity and immunosuppressive properties of infectious bursal disease intermediate strains. Avian Dis., 34: 302-308.

Mcilory, S. G.; Goodall, E. A. and McCracken, R. M. (1989): Economic effects of subclinical infectious bursal disease on broiler production. Avian Pathol., 18 (3): $465-$ 475.

Mona, M. A. (2002): Studies on epidemiology and vaccination for prevention of Gumboro disease in chickens. Ph.D. Thesis. Fac. Vet. Med., Cairo Univ. (Beni-Suef branch).

Naqi, S. A.; Marquez, B. and Shahin, N. (1983): Maternal antibodies and its effect on infectious bursal disease immunization. Avian Dis., 27 (3) 623-630.

Naqi, S. A.; Millar, D. L. and Grumbles, L. C. (1980): An evaluation of 3 commercially available infectious bursal disease vaccines. Avian Dis., 24 (1): 233-240.

Nunoya, T.; Otaki, Y.; Tajima, M.; Hiraga, M. and Saito, Y. (1992): Occurrence of acute infectious bursal disease with high mortality in Japan and pathogenicity of field isolates in SPF chickens. Avian Dis., 36: 597-609.

Okoye, J. O. A. (1984): Infectious bursal disease of chickens. Vet. Bullt., 54 (6): 425-436.

Okoye, J. O. A. and Uzoukwu. A. (1981): An outbreak of infectious bursal disease among chickens between 6 and 20 weeks old. Avian Dis., 25 (4): 1034-1038.

O'Brien, A. (1976): Infectious bursal disease of chickens and vaccination. Vet. Rec.,20: 260-261.

Reed, L. J. and Muench, H. (1938): A simple method of estimating fifty per cent end point. Amer. J. Hyg., 27: 493497.

Rinaldi, A.; Cessi, D.; Cervio, G. and Lodetti, E. (1974): Attenuation of infectious bursal disease virus and vaccination trials under laboratory and field conditions. Avian Pathol., 3 (1): 51-57.

Roasales, A. G.; villegas, P.; Lukert, P. D.; Fletcher, O. J. and Brown, J. (1989):

Immunosuppressive potential and pathogenicity of recent isolates of infectious bursal disease virus in commercial broiler chickens. Avian Dis., 33: 724-728.

Rosenberger, J. K. and Cloud, S. S. (1986): Isolation and characterization of variant infectious bursal disease viruses. J. Amer. Vet. Med. Ass., 189: 357.

Rosenberger, J. K.; Cloud, S. S. and Metz, A. (1987): Use of infectious bursal disease virus variant vaccines in broilers and broiler breeders. Proc. $36^{\text {th }}$ West Poultry Dis. Conf., 105-109.

Saif Y. M.; Barnes, H. J.; Fadly, A. M.; Glisson, J. R. and Swayne, D. E. (2003): Infectious bursal disease, in Poultry Diseases, $11^{\text {th }}$ Ed., Iowa State Press, Iowa.

Shaban, K. S. (2004): Studies on avian infectious proventriculus disease. Ph.D. Thesis. Fac. Vet. Med., Cairo Univ.

Sharma, J. M.; Dohms, J. E. and Metz, A. L. (1989): Comparative pathogenesis of serotype- 1 and variant serotype-1 isolates of infectious bursal disease virus and their effect on humeral and cellular immune competence of SPF chickens. Avian Dis., 33: 112-124.

Snedeker, C.; Wills, F. K. and Moulthrop, I. M. (1967): Some studies on the infectious bursal agent. Avian Dis., 11: 519-528.

Solano, W.; Giambrone, J. J.; Williams, J. C.; Lauerman, L. H; Panagala, V. S.

and Garces, C. (1986): Effect of maternal antibodies on timing of initial vaccination of young white leghorn chickens against infectious bursal disease virus. Avian Dis., 30: 648-652.

Steel, R. G. D. and Torrie, J. H. (1960): Principles and procedures of statistics. McGraw-Hill Book Comp. Inc. New York, Toronto, London, PP. 99-131.

Sultan, H. A.; El-Balal, S.; Husseien, H. A. and Abdel Razek, A. (2006): 
Development of early protection induced by intermediate and intermediate plus infectious bursal disease virus (IBDV) vaccines against very virulent IBDV (vvIBDV). Proceedings of the $7^{\text {th }}$ Sci. Conf. of the Egypt. Vet. Poult. Asso. (pp. 227-238). Cairo, Egypt.

Thangavelu, A.; Dhinakarraj, G.; Elankumaran, S.; Murali Manohar, B.; Koteeswaran A. and Venugopalan, A. T. (1998): Pathogenicity and immunosuppressive properties of infectious bursal disease virus field isolates and commercial vaccines in India. Tropical Anim. Health and Prod., 167-176.

Thornton, D. H. and Pattison, M. (1975): Comparison of vaccines against infectious bursal disease virus. J. Comp. Pathol., 85: 597-610.

Tsukamoto, K.; Tanimura, N.; Kakita, S.; Ota, K.; Masc, M.; Imai, K. and

Hihara, H. (1995): Efficacy of 3 live vaccines against highly virulent infectious bursal disease virus in chickens with or without maternal antibodies. Avian Dis., 39: 218229.

Van den Berg, T. P. and Meulemans, G. (1991): Acute infectious bursal disease in poultry: protection afford by maternally derived antibodies and interference with live vaccination. Avian Pathol., 20 (3): 409-421.

Van den Berg, T. P.; Gonze, M. and Meulemans, G. (1991): Acute infectious

bursal disease in poultry, isolation and characterization of a highly virulent strain. Avian Pathol., 20: 133-143.

Villegas, P. and Purchase, G. (1989): Titration of biological suspension. In: Laboratory Manual for the
Isolation and Identification of avian pathogens. $3^{\text {rd }}$ ed. American Association of Avian Pathologists. H. G. Purchase, L. H. Arp., C. H. Domermuth and J. E. Pearson eds. Kenell/Hunt publishing company, Iwo, USA. Pp. 186190.

Winterfield, R. W. and Thacker, H. L. (1978): Immune response and pathogenicity of different strains of infectious bursal disease virus applied as vaccines. Avian Dis., 22 (4): 721-731.

Winterfield, R. W.; Dhillon, A. S.; Thacker, H. L. and Alby, L. J. (1980): Immuneresponse of white leghorn chicks from vaccination with different strains of infectious bursal disease virus and in the presence of maternal antibodies. Avian Dis., 24 (1): 179-188.

Winterfield, W. R.; Fadly, A. M. and Bickford, A. (1983): Infectivity and distribution of infectious bursal disease virus in chickens, persistence of the viruses and lesions. Avian Dis., 16: 622-632.

Wood, G. W.; Muskett, J. C. and Thronton, D. H. (1983): Use of inactivation oil emulsion vaccine in breeder chickens to prevent immunosuppression in progeny chicks. Res. Vet. Sci., 35: 114-115.

Wyeth, P. J. and Chettle, N. J. (1990): Use of infectious bursal disease vaccine in chicks with maternally derived immunity. Vet. Rec., 126: 577-578.

Wyeth, P. J. and Cullen, G. A. (1978): Transmission of immunity from inactivated infectious bursal disease oil emulsion vaccinated parent chickens to their chicks. Vet. Rec., 102: 362-363.

\section{كفاءة لقاحات التهاب غدة فبريشس المعدى الحية فى تحصين كتاكيت تجارية عمر · ا يوم}

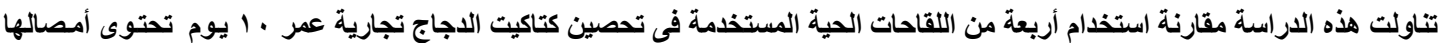

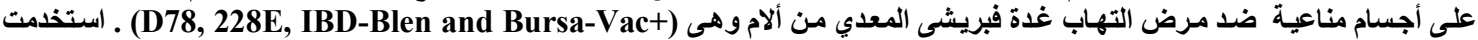

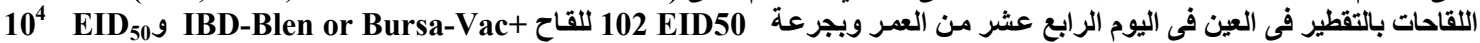

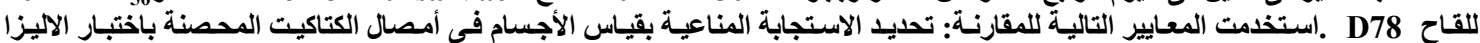
ELISA test

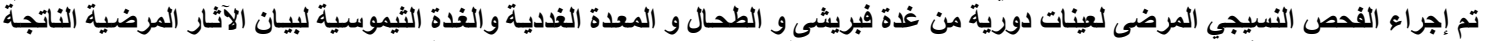

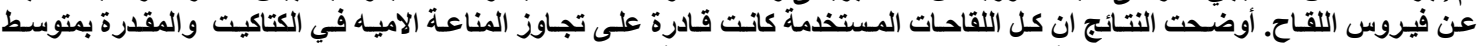

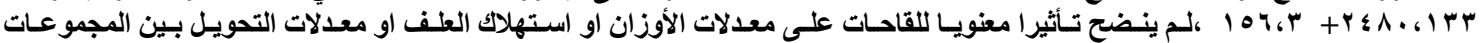

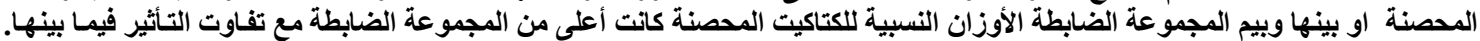

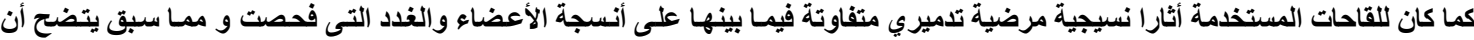

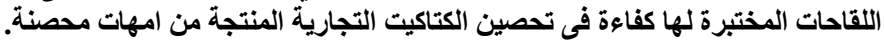

